This is the peer reviewed version of the following article: Bardhan, I., Krishnan, V. V. and Lin, S. (2013), Team Dispersion, Information Technology, and Project Performance. Prod Oper Manag, 22: 1478-1493. doi:10.1111/

j.1937-5956.2012.01366.x, which has been published in final form at http://dx.doi.org/10.1111/j.1937-5956.2012.01366.x.

This article may be used for non-commercial purposes in accordance with Wiley Terms and Conditions for Self-Archiving.

\title{
Team Dispersion, Information Technology, and Project Performance
}

\author{
Indranil Bardhan \\ School of Management, SM 41, The University of Texas at Dallas, Richardson, Texas 75083-0688, USA, bardhan@utdallas.edu \\ Vish V. Krishnan \\ Rady School of Management, University of California, San Diego, La Jolla, California 92093, USA, vkrishnan@ucsd.edu
}

Shu Lin

Craig School of Business, California State University, Fresno, California 93740, USA, shulin@csufresno.edu

\begin{abstract}
$\mathrm{T}$ he impact of information technology (IT) on the performance of distributed projects is not well understood. Although prior research has documented that dispersion among project teams has an adverse effect on project performance, the role of IT as an enabler of communication to bridge the spatial distance among team members in distributed networks has not been empirically studied. We focus on the role of IT as a moderator of the relationship between team dispersion and project performance using projects as the unit of analysis. We find that IT mitigates the negative effect of team dispersion on project performance, especially in high information volume projects. Our central contribution is the development of an empirically tested model to improve the understanding of the operational impact of IT as a vehicle to bridge spatial dispersion among distributed teams that are engaged in knowledge-intensive work.
\end{abstract}

Key words: team dispersion; information technology; project performance; moderation; project management

\section{Introduction}

Distributed project management, in which more than one geographic location contributes to the planning, execution, and delivery of projects, is a growing practice in many companies and industries (Bala et al. 2010). Projects pursued in distributed fashion range from transactional business process outsourcing to higher-level design and development projects (Amaral et al. 2011). The rise of Internet-enabled information technologies is an important contributing factor to the global distribution of projects. Most studies in the information technology (IT) literature have focused on the impact of IT at the level of the firm or business unit, instead of the level of the project. As projects have emerged as important vehicles for firms to realize unique and innovative services (and evaluate funding decisions), the focus of our study is on the mechanisms through which IT may impact the performance of distributed projects.

Information technology has delivered significant productivity improvements in the manufacturing sector of the economy (Banker et al. 2006a, Barua et al. 1995, Weill 1992). Improving the productivity of knowledge-intensive work, typically associated with product and project management, is the next frontier for IT applications. Delivering information and knowledge work - defined as the "creation, coordination, integration and management of knowledge and information within a firm and its extended value network" (Conner and Prahalad 1996)—requires effective project management capabilities. With the increasing distribution of markets and labor pools, ITenabled services are called upon to manage projects that are dispersed worldwide separated by distance and time. However, there is a lack of empirical evidence about the effectiveness of distributed projects and the impact of IT on the performance of dispersed project teams.

Despite its increasing role and importance, the conditions under which IT enables the productivity of knowledge-intensive work in general and projects in particular is not well understood (Metters and Maruchek 2007). The intangibility and diversity of knowledge-intensive work, typical of most projectmanagement settings, presents unique challenges in description, measurement, and improvement (Erat and Krishnan 2012, Wu et al. 2010). To develop a finer understanding of the business value of IT and its role in managing globally dispersed project teams, we 
focus on enterprise projects, which represent vehicles through which the output of knowledge work is realized.

We draw on prior research on virtual teams and the role of technology in managing communication in product design and development to study how IT contributes to improvements in project performance when project teams are distributed across space (Eppinger and Chitkara 2006, Maznevski and Chudoba 2000, Song et al. 2007). Our research questions are two-fold: (i) how does dispersion of project teams affect project performance? and (ii) Does IT usage mitigate the effect of team dispersion on project performance? In other words, our focus is on exploring the conditions under which IT has an impact on project outcomes.

We validate our research using survey data from project managers drawn from a large cross-section of US firms. ${ }^{1}$ Our study reveals several important findings. First, our results indicate that project team dispersion is negatively associated with project performance. In other words, project teams that are widely dispersed across different locations are more likely to exhibit lower levels of project quality, ontime completion rate, and longer cycle times. Second, we find that IT usage moderates the negative effects of team dispersion on project performance. We also observe that the mitigating effect of IT is positive and significant in high information volume environments. In other words, our results suggest that IT can alleviate the negative effects of spatial dispersion of project teams by enabling collaboration and information exchange that allows team members to function in a more effective manner. While breaking new ground on the hitherto under-researched domain of the coordination and information exchange challenges that are typical of project management work, we provide empirical evidence related to the role of IT as moderator of the relationship between team dispersion and project performance. Our study sheds new light on the role of IT as an enabler of distributed project management and the specific context in which IT can improve project performance (Amaral et al. 2011).

\section{Theoretical Foundation}

During the 1980s and 1990s, it was widely believed that best practices in product development project management involved co-location of cross-functional teams to enable collaboration, coordination, and concurrent information processing across engineering, marketing, manufacturing, and supply-chain operations (Ancona and Caldwell 1992, Eppinger and Chitkara 2006, McKelvey et al. 2003). Reducing the spatial distance between project team members has been widely believed to result in more frequent communi- cation, and associated with better product development performance. The R\&D literature indicates that good technical communication with the $R \& D$ organization is an important determinant of R\&D productivity (Allen 1977, 2007, Krishnan and Loch 2005, Krishnan and Ulrich 2001). Co-location of R\&D teams improves inter-personal communication with other teams working on different projects, which fosters an open exchange of ideas, and enables cooperation and integration of $R \& D$ with other business functions, such as marketing, manufacturing, and supply chain operations (Griffin and Hauser 1996, Kahn and McDonough 1997).

Conventional wisdom holds that dispersion of team members may hinder face-to-face communication and exacerbate other barriers to communication, such as encouraging technical jargon and increasing perceptions of personality differences (Griffin and Hauser 1996). Maltz and Kohli (1996) report that managing the physical separation between R\&D and marketing teams can be an important element in enhancing cross-functional information dissemination. Research in organizational economics research has observed that centralization of R\&D improves innovation output, as it economizes the coordination costs when there exist economies of scope in R\&D (Argyres and Silverman 2004). The complexities of a distributed environment, specifically the challenges of integration, have been examined in a review article by Anderson and Parker (2012). In response to these challenges, some organizations have responded by co-location of all activities under one roof (Becker and Steele 1995, Stalk and Hout 1990).

On the other hand, proponents of the "knowledgebased view" school of thought have argued that multiple, dispersed R\&D locations allow firms to adapt existing technological knowledge to new markets and access locally available sources of knowledge to improve firm innovation capabilities (Furman et al. 2006, Grant 1996, Kogut and Zander 1993). The knowledge-based view of the firm posits that multilocation of R\&D through distributed teams improves external knowledge sourcing, although it raises costs of communication and coordination (Chacar and Lieberman 2003, Singh 2008). Based on their analysis of unique firm-level data on R\&D activity and innovation output, Leiponen and Helfat (2011) report that the multi-location of R\&D teams is positively associated with greater innovation output and is correlated with external knowledge sourcing. Their research suggests that dispersion of project teams involved in $\mathrm{R} \& \mathrm{D}$ is associated with greater innovation activity, although they do not directly measure the extent of technological capabilities involved in coordination across teams. 
Empirical evidence to support the association between team dispersion and product development performance has been mixed. Although Allen's (1977) seminal study reported that communication increases by co-locating R\&D teams, there have been few empirical studies that have documented evidence of the relationship between team dispersion and project performance. Based on their research conducted within the Belgian subsidiary of a large US telecom provider, Van den Bulte and Moenaert (1998) found that although communication among R\&D teams increased after co-location, the communication frequency between R\&D and marketing functions was not affected by increased physical distance. Their results suggest that "... organizational procedures and systems can compensate for some of the negative aspects traditionally associated with locating some units apart from the rest of the corporation..." (Van den Bulte and Moenaert 1998, p. s15). Their research implies that coordination and administrative tasks for project management may well be suited for "virtual co-location," whereby IT can be used to integrate project teams across functional areas of the enterprise.

During the past decade, information, and knowledge work in general, and product development projects in particular, have become globally distributed and inter-networked (Krishnan and Loch 2005, Parker and Anderson 2002). The reasons cited for such distribution include cost savings, capacity enhancement, access to foreign markets, and $24 \times 7$ asynchronous project execution (Bala et al. 2010, Bas and Sierra 2002, Kumar 2001). In the globally distributed model of product development, some functions are centralized while engineering and related product design functions are distributed to other sites dispersed worldwide (Majchrzak et al. 2000, Schmidt et al. 2001). This practice involves a combination of outsourced and captive offshore engineering facilities. Hence, global product development is characterized by a coordinated operation that includes distributed teams in multiple countries enabled by an IT-enabled digital infrastructure that supports a collaborative product development process (Sanders 2007). To mitigate the negative effects of such distribution on team communication, companies have increasingly turned to modular architectures and new types of technologies that can facilitate synchronous and rich exchange of project data (Krishnan and Ramachandran 2011).

Song et al. (2007) study the effect of computer-mediated communication (CMC) technologies and colocation of R\&D staff using a cross-sectional sample of 277 high-tech firms in the United States. They report that although CMC technologies and co-location were associated with greater knowledge dissemination among $R \& D$ staff, their joint effect also strengthened the overall level of knowledge dissemi- nation. Although they do not observe the effects on project-specific performance, their findings suggest that IT and co-location increased each other's value, especially when interdependent tasks require appropriate technologies to facilitate heterogeneous knowledge-sharing across R\&D team members.

Prior research on geographically dispersed teams has explored various dimensions of dispersion including space, time, configuration, and socio-demographic characteristics that have an impact on team processes and performance (Cramton and Hinds 2005, Griffith et al. 2003, O'Leary and Mortensen 2010, Polzer et al. 2006). The proliferation of global project teams operating across greater distances has heightened the focus on the work of geographically dispersed teams and the technologies that they use to communicate and coordinate project work ( $\mathrm{O}^{\prime}$ Leary and Cummings 2007). However, few studies have investigated the various types of information technologies that are used to manage project teams and evaluate under what conditions IT may be beneficial in terms of its impact on project outcomes. Based on our review of the extant literature on geographic dispersion in teams, we argue that there is a dearth of evidence on the role of IT in terms of mitigating the potentially negative effects of team dispersion on project-level performance. Furthermore, there is a need to identify the types of project characteristics that lend themselves to successful application of IT, and the conditions wherein IT usage may have a significant impact on project outcomes. Our empirical study of project-level data, collected across a wide cross-section of projects from multiple industries, represents an important first step in addressing these research questions.

\section{Research Hypotheses}

We now develop our model of how distributed project performance is impacted by IT, before testing the model with field data.

\subsection{IT Usage and Project Performance}

Enterprise information systems can potentially enable firms to improve the consistency of project execution by enabling greater visibility to project data and allowing managers to track progress more easily (Sanders 2007). Firms invest in CRM systems to enable managers to identify and disseminate customer requirements in a timely manner and facilitate greater customer participation in project decisions. In a similar vein, knowledge management systems enable project managers to identify emerging market trends and develop relevant product enhancements. Individual-level communication tools, such as e-mail and instant messaging, enable project teams to solicit customer and supplier input into key project 
decisions, which can lead to improvements in the quality of such decisions. Similarly, group collaboration technologies facilitate quicker exchange of mission-critical data, and thereby allow project managers to effectively leverage their use of knowledge assets across distributed teams (Bardhan et al. 2007a).

Newer IT applications help R\&D managers improve the effectiveness of their innovation processes by enabling capabilities to harness the knowledge embedded across dispersed project teams and enable easier (and faster) access to critical product data that help to reduce project cycle time and overall project costs. In the pharmaceutical sector, advances in computing power and software support highthroughput screening, thereby compressing the biological and chemical phases of the drug discovery value chain into one parallel phase. A recent study by McKinsey reports that pharmaceutical companies, which use IT in clinical trials processes, increased their overall productivity by improving the speed, quality, and costs associated with their R\&D projects (Marwaha et al. 2007). In light of the increasing role of IT in managing projects, we hypothesize that greater IT usage will be associated with improvements in project performance.

H1. Greater usage of information technology is associated with improvement in project performance.

\subsection{Team Dispersion and Project Performance}

Prior studies have documented the positive relationship between the level of internal technical communication among project teams and organizational performance (for an archetypal study on this vast literature, see Sosa et al. 2007). ${ }^{2}$ Physical proximity is an important factor in improving the quality of communication within and across project teams as it increases the likelihood of learning from those with knowledge of developments within the organization. Prior research has found that as the spatial distance between teams increases, their frequency and effectiveness of communication diminish significantly (Allen 1977, O'Leary and Mortensen 2010). Teams spanning multiple time zones and spatial distance often exhibit inter-site communication failures and experience major challenges in coordinating project schedules and deliverables (Espinosa and Pickering 2006, Kiesler and Cummings 2002, Saunders et al. 2004). Their findings imply that physical distance between project personnel strongly influences the extent of communication between team members, thus compromising the effectiveness of project coordination and integration.

Using data from a quasi-experiment conducted with R\&D teams within an industrial organization,
Van den Bulte and Moenaert (1998) report that the quality of communication among R\&D teams was enhanced after co-locating these teams. Their findings imply that the effect of co-location depends on the content and information medium used for communication. Similarly, Sosa et al. (2002) note that co-location within $R \& D$ teams enhances the performance of new product development, potentially reducing misalignment with the product/market outcomes (Sosa et al. 2004, Ulrich and Ellison 2005). Argyres and Silverman (2004) observe that R\&D work that is not characterized by economies of scope (such as more applied and market-oriented R\&D) is more likely to be conducted across geographically dispersed teams and exhibit greater communication and coordination challenges. The coordination costs of such projects are likely to be high as they require effective integration of dispersed teams across multiple geographical locations and cultures (Amaral et al. 2011, O'Leary and Cummings 2007). Hence, we posit that team dispersion (inverse of co-location) is detrimental to project teams' ability to reduce variability in project performance, communicate changes to customer data, and improve output quality. In other words, we hypothesize that team dispersion is negatively associated with project performance.

H2. Greater dispersion within project teams is associated with lower levels of project performance.

\subsection{Moderating Role of IT}

Increasingly, effective project execution requires the rapid sharing of knowledge within and across organizations and individuals (Bensaou and Earl 1998, Massey et al. 2003). During the past decade, globalization has had a major impact on the practice of project management across all industries. A fundamental paradigm shift has occurred from the prevailing practice of co-locating teams to a new model, wherein companies utilize skilled project teams dispersed across the globe to develop products and services and manage projects in a collaborative manner (Banker et al. 2006b). Eppinger and Chitkara (2006) have coined the phrase "Global Product Development" to refer to the emerging best practice of global collaboration across virtual teams that are involved in creating new products and services (Martins et al. 2004).

Information technologies mitigate the negative effects of distance by providing the richness of a communication medium for project team members to collaborate with each other (Massey and MontoyaWeiss 2006). Media richness theory argues that the richness of a communication medium determines its ability to reduce uncertainty and resolve ambiguity, and influences the capacity of the user(s) to build 
meaningful relationships (Daft and Lengel 1986). IT also helps knowledge dissemination by enabling project teams to share both explicit and tacit knowledge (Song et al. 2007). While the first generation of CMC technologies, such as email, groupware, and video-conferencing technologies, were adequate in terms of their ability to facilitate asynchronous information exchange, newer types of Web 2.0 technologies, such as collaboration software and IP-based video conferencing, allow synchronous exchange of project information (Bardhan et al. 2007a). Such technologies also enable team members to share richer technical knowledge by enabling intensive real-time interaction between teams, allowing them to build deeper relationships, and provide feedback mechanisms for effective collaboration (Banker et al. 2006b).

Information technologies can overcome the spatial distance constraints imposed by dispersed project teams by providing a multitude of capabilities, including communication, visualization, calculation, and simulation tools that enable creation of new product knowledge (Yassine et al. 2004). Collaboration software enables product design teams to collaborate across inter-organizational boundaries to gather and share design requirements, conduct design iterations, verify and test product designs, and provide the final design hand-offs to other departments (Adler 1995, McGrath and Iansiti 1998). They support a broad range of system-to-system collaboration capabilities for processing of structured and unstructured product design data (Baba and Nobeoka 1998, Nambisan 2003). Recent research suggests that rich media may be particularly important where time to market is a critical factor and multiple parties must conduct complex activities in an integrated manner. Based on a study of third-party logistics companies, Vickery et al. (2004) showed that media rich communications have a positive effect on customer relational performance by enabling communication capabilities that strengthen customer-supplier relationships. Hence, we argue that IT enables project teams to mitigate the negative effect of team dispersion on project performance.

H3. IT usage moderates the negative influence of team dispersion on project performance.

Based on archival data collected across a cross-section of firms, Allen (2007) finds that the type of communication medium used to exchange information within organizations depends on the complexity and volume of information. We argue that rich communication media permit transmission of complex knowledge among project teams (Vickery et al. 2004, Yassine et al. 2004). Product development environments exhibit a high frequency and volume of information exchange, which is characterized by greater complexity and turbulence arising from project interdependencies that result in design changes and new interfaces (Hinds and Kiesler 1995, Hoegl et al. 2004). New types of web-enabled collaboration technologies provide the information-rich infrastructure that facilitates synchronous communication within and across project teams.

For high information volume project work, groupware and collaboration technologies enable synchronous communication that helps team members to synchronize each other's work and adapt to changing organizational conditions. In such projects, enabling technologies can serve as a medium for real-time synchronization of information and provide instantaneous feedback on project data using threaded discussion databases, instant messaging, and other groupware. Hence, we argue that the moderation effect of IT will be much greater in high information volume environments as compared with other settings where the volume of information exchange is relatively low.

H3a. The moderation effect of IT on team dispersion and project performance is greater in high information volume projects compared with low information volume projects.

We control for several factors to account for the impact of project and firm characteristics on project performance. Team size dictates the extent of information processing across project teams. Project team size may have an impact on the ability of teams to realize improvements in project outcomes, as smaller teams that are co-located may be more agile in responding to shifting market trends compared with dispersed teams. At the same time, larger teams can leverage greater scale economies and access to a broader range of skills to improve performance. Autonomy of project decision making can determine the extent to which a team can swiftly respond to changes in project and market requirements without requiring formal approval from senior management (Mendelson 2000). We also control for project duration as longer projects may require different types of team coordination capabilities and information processing requirements compared with shorter projects. As different industries are characterized by varying levels of information processing requirements, we control for industry in our estimation to account for the variability in project performance across different industry environments.

We also control for process maturity to account for differences in process management practices across projects. Greater levels of process maturity are associated with adoption of mature project management practices to support product development integration 
strategies and use of quantitative targets to manage projects, mitigate risk, coordinate training, and manage key stakeholders (Krishnan et al. 2000). The rationale is that, by adopting practices which increase process capabilities, product defects can be detected earlier in the project lifecycle which reduces rework to correct errors in later stages (Terwiesch et al. 2002).

Our conceptual research model and hypothesized relationships are shown in Figure 1.

\section{Research Data}

First, we describe our data collection strategies for obtaining project-specific data from project managers across a large cross-section of US firms. Next, we discuss variable definitions and our procedures for measurement based on the survey data.

\subsection{Data Collection}

We designed a research survey to capture data on project characteristics, IT usage, team dispersion, project performance, as well as information on firm characteristics. A cross-sectional survey was used for data collection, and administered online through an independent, professional survey firm to a random sample of project and product managers, drawn from their business-to-business panel of North American private- and public-sector organizations. The survey firm is one of the largest, international, online panel survey firms involved in a variety of market research and online panel data collection studies. Their sampling was based on screening criteria that we provided to ensure that (i) adequate coverage was obtained from a broad cross-section of industries and (ii) that the primary respondent be an experienced project manager with at least 1 year of project management experience. Respondent validation was required through address verification, and the sampling population was defined as decision makers who

Figure 1 Conceptual Research Model

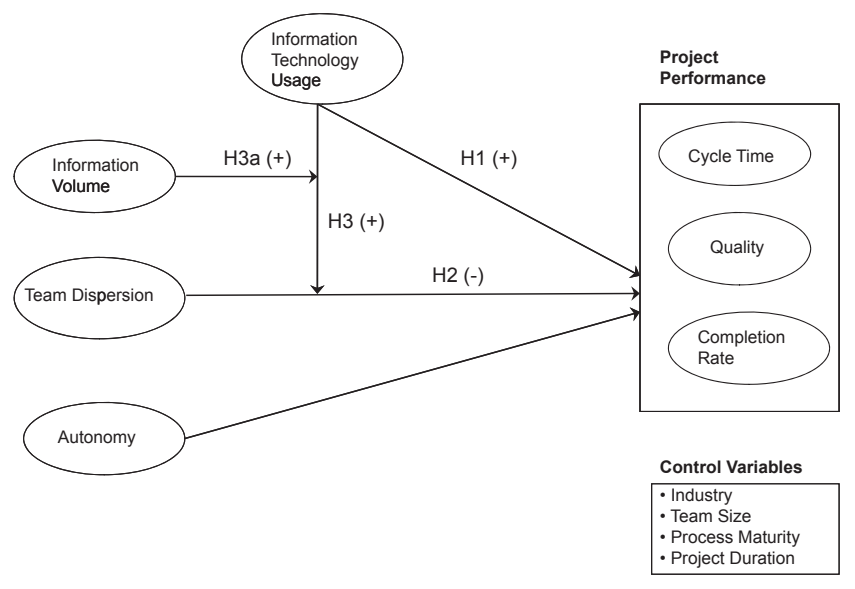

manage or lead business projects. These decision makers were drawn from many business areas, including administration, customer service, sales, operations, finance, engineering, account management, production, and R\&D. Our survey instrument is shown in the Online Appendix.

Content validity of our questionnaire was established by initially testing it with several project managers in a few firms, including a pharmaceutical firm, a construction management company, a high-tech firm, and a few members of the Project Management Institute (PMI). We assessed the substantive validity of our survey items and model constructs through a post hoc validation using Q-sort analysis that was conducted on a small group of 20 project managers. A first phase of pilot data was followed by a final data collection effort in June 2004 which yielded 780 responses. The final dataset of 637 respondents represents completed surveys where the respondents met key survey screening criteria. The overall response rate to our web-based survey was $17 \%$, which is consistent with other large operations surveys in the literature (Miller and Roth 1994). Respondents provided demographic information about their areas of responsibility, job title, company type, annual revenue, and industry affiliation. Table 1 shows the profiles of project managers (i.e., survey respondents) based on their industry and firm affiliations, as well as other project-specific characteristics, such as the primary business process that the project supports as well as project team size.

We observe that a project, defined as a collection of activities that have been established to complete a specific goal, represents our unit of analysis in this research (Tatikonda and Montoya-Weiss 2001). Our dataset consists of projects that support business processes including operations and supply chain, IT, HR, finance and accounting, sales and marketing, $R \& D$, and administration. The survey design allows us to observe the firm characteristics of respondents who abandoned or terminated the survey prior to completion. Non-response bias was assessed by comparing the percentage of complete responses for each of the "firm revenue" and "team size" categories in our survey. A chi-square test indicates that there does not exist a statistically significant difference in the response rates of firms across different revenue categories $\left(\chi^{2}=10.54 ; p\right.$-value $\left.=0.13\right)$. Similar results were obtained when non-response bias was assessed based on survey response rates according to project team size $\left(\chi^{2}=5.15 ; p\right.$-value $\left.=0.27\right)$.

As our survey data are self-reported, we performed Harmon's one-factor test to check for common method bias (Podsakoff et al. 2003). The items that represent independent variables and those that measure project performance load on different factors. We 
Table 1 Distribution of Projects by Industry, Firm Type, and Team Size

\begin{tabular}{|c|c|c|}
\hline & Number of respondents & $\%$ \\
\hline \multicolumn{3}{|l|}{ Industry } \\
\hline Communication & 54 & 8.49 \\
\hline Energy & 21 & 3.30 \\
\hline Financial services & 73 & 11.48 \\
\hline Healthcare & 70 & 11.01 \\
\hline Public sector & 110 & 17.30 \\
\hline Manufacturing & 118 & 18.55 \\
\hline Retail/wholesale & 55 & 8.65 \\
\hline Travel and transportation & 24 & 3.77 \\
\hline $\begin{array}{l}\text { Other (Real estate, hospitality, } \\
\text { consulting, etc.) }\end{array}$ & 111 & 17.45 \\
\hline \multicolumn{3}{|l|}{ Firm revenues } \\
\hline$\$ 10$ million to $\$ 49.9$ million & 91 & 14.31 \\
\hline$\$ 50$ million to $\$ 99.9$ million & 62 & 9.75 \\
\hline$\$ 100$ million to $\$ 499.9$ million & 75 & 11.79 \\
\hline$\$ 500$ million to $\$ 999.9$ million & 47 & 7.39 \\
\hline$\$ 1$ billion to $\$ 9.9$ billion & 99 & 15.57 \\
\hline$\$ 10$ billion or more & 92 & 14.47 \\
\hline Not for profit & 73 & 11.48 \\
\hline $\begin{array}{l}\text { Don't know/Not at } \\
\text { liberty to disclose }\end{array}$ & 97 & 15.25 \\
\hline \multicolumn{3}{|l|}{ Project type } \\
\hline Administration & 64 & 10.06 \\
\hline Finance and accounting & 42 & 6.60 \\
\hline Information technology & 83 & 13.05 \\
\hline Operations & 335 & 52.67 \\
\hline Sales and marketing & 59 & 9.28 \\
\hline Other & 53 & 8.33 \\
\hline \multicolumn{3}{|l|}{ Project team size } \\
\hline 2-10 people & 373 & 58.65 \\
\hline 11-20 people & 122 & 19.18 \\
\hline 21-50 people & 83 & 13.05 \\
\hline 51-100 people & 27 & 4.25 \\
\hline >100 people & 31 & 4.87 \\
\hline Total & 636 & 100 \\
\hline
\end{tabular}

also applied the method factors test, which suggests that common methods bias is not an issue (Williams et al. 1989).

\subsection{Variable Construction}

Table 2 describes the variables of interest in our study and their measurement scales. We develop the construct, ITUSAGE, based on a summative index that consists of 11 types of information technologies that are commonly used for project management. These technologies support project communication, data management, and decision support within organizations, and consist of a mix of simpler communication technologies as well as enterprise and group collaboration systems. The summative score, with a range of $1-5$, measures the degree of usage of various IT applications, with 1 representing "No use" and 5 representing "Heavy usage" of an application. The average score of the 11 IT application indicators was calculated to develop the summative index. Our use of the summative index to measure variations in IT usage across different types of IT applications is consistent with other empirical measures of IT usage in the manufacturing and healthcare industries, respectively (Bardhan et al. 2007b, Himmelstein et al. 2010).

Information Volume (VOLUME) represents the volume of input information and amount of information processing that is required to complete a major project milestone, and is measured as a summative score based on the average value of its indicators. Team Dispersion measures the extent of dispersion among project team members. Higher values represent distributed project teams while lower values represent teams that are located in one location (Sosa et al. 2002). Autonomy measures the extent to which project teams have autonomy from management in making project decisions, in line with the definition proposed by Mendelson (2000).

We define three dimensions of project performance that represent observed year-over-year change in project cycle time, quality, and completion rate. Cycle time represents the change in project cycle time incurred from project initiation to completion. Quality represents the change in project quality, measured as the total number of errors and rework associated with the project, whereas On-time completion rate represents the percentage of project milestones that are completed on a timely basis. Table 3 provides descriptive statistics of our model variables, including the Spearman/ Pearson correlation matrix of our model variables. We used the SAS statistical software for estimation of our regression models, and specified the variance inflation factor (VIF) and COLLINOINT options to check for multi-collinearity. As a rule of thumb, a large VIF number, 10 or more, is an indication of collinearity (Belsley et al. 1980). Our VIF results indicate that the VIF values on most variables is less than two, with the largest condition index in our model taking on a value of 3.16. Hence, our data do not indicate presence of multi-collinearity.

We control for the impact of project team size, autonomy, duration, process maturity, and industry type on project performance. Team size measures 0 the number of full-time equivalent staff on the project team. Autonomy measures the extent to which teams have autonomy from management in making project decisions (Mendelson 2000). Project duration measures the overall time frame of the project from start to completion measured in years. Process maturity measures the extent of adoption of advanced management practices for project planning, execution, and management, which includes competitive benchmarking of best practices, and appropriate training and leadership in the use of work methods, processes, and IT (Harter et al. 2000). The process maturity indicators load on a single factor (PROCMAT) based on statistical tests that we conducted using principal component analysis. 
Independent variables

IT Usage

Dispersion

Autonomy

Team Size

Process Maturity

(Factor)

Project Duration

Information Volume

Dependent variables

Cycle Time

Quality

On-Time

Completion Rate
A summative index that measures the degree of usage of various IT applications. The score is an average of 11 survey items with values ranging from 1 to 5 ( 1 = No use, $2=$ Limited use, $3=$ Medium use, $4=$ High use, and $5=$ Heavy use). The IT applications include: Instant Messaging Software; Mobile Computing (Tablets, PDA, Palm hand-helds, Blackberry hand-helds); Enterprise Application Software (ERP, Supply Chain Management, Financials); Knowledge Management software; Business Intelligence software (e.g., SAS, Hyperion, Cognos); Customer Relationship Management (CRM, Collaboration Tools) software; Project Management software; Content Management Systems/Project Portals; Video-Conferencing and Voice over IP (VoIP) Technologies (Webex); Document Management Solutions/Systems; and Groupware and Online Teamspaces (e.g., Sharepoint, LiveLink, and eRoom)

An ordered variable measuring the extent of dispersion of the project team: $1=$ Same Building, 2 = Same City, $3=$ Same Time Zone, 4 = Different Time Zones, and $5=$ Different Country and Time Zone

An ordered variable that measures the organizational level at which decisions related to project targets/goals are made: 1 = Business unit head, 2 = Program sponsor, $3=$ Project manager, and $4=$ Project team

An ordered variable that measures the size of project team:

$1=1-10$ people, $2=11-20$ people, $3=21-50$ people, $4=51-100$ people, and $5=$ greater than 100 people

A factor score that measures the extent to which best practices for effective project management have been adopted. Indicator variables consist of the following survey questions: (i) We have well-defined processes for program/project execution; (ii) Quantitative targets are used to manage program/projects; (iii) Metrics are automatically collected for process management; (iv) Customer feedback is collected, tracked, and used for continuous process improvement; (v) We benchmark our performance against best-practices from other industries; (vi) Program/Project personnel are well-trained in the use of work methods and practices; and (vii) New or updated methods, practices, and information systems are used to keep project teams in touch with customers. The scale for survey items (1) through (4) is defined as follows: $1=$ Never, $2=$ Rarely, $3=$ Sometimes, $4=$ Frequently, and $5=$ All the time. The scale for survey items (5) through (7) is defined as follows: $1=$ Strongly Disagree, $2=$ Disagree, $3=$ Neutral, $4=$ Agree, and $5=$ Strongly Agree

An ordered variable that measures the average duration of project: $1=<1$ year, $2=1-2$ years, $3=3-5$ years, $4=6-10$ years, $5=>10$ years

A summative score that measures the volume of information required to complete the project. The score is an average of the following ordered variables: (i) Volume of input information that is required to complete a major project, and (ii) Volume of information processing required to complete a major project milestone

An ordered variable that measures year-over-year change in project cycle time: $1=$ Increased more than $80 \%, 2=$ Increased $41-80 \%, 3=$ Increased $1-40 \%, 4=$ No change, $5=$ Decreased $1-40 \%, 6=$ Decreased $41-80 \%, 7=$ Decreased more than $80 \%$

An ordered variable that represents year-over-year change in project quality as measured by the number of project errors and extent of rework: $1=$ Decreased more than $80 \%, 2=$ Decreased $41-80 \%, 3=$ Decreased $1-40 \%, 4=$ No change, $5=$ Increased $1-40 \%, 6=$ Increased $41-80 \%, 7=$ Increased more than $80 \%$

An ordered variable that measures year-over-year change in the percentage of projects completed on-time: $1=$ Decreased more than $80 \%, 2=$ Decreased $41-80 \%, 3=$ Decreased $1-40 \%, 4=$ No change, $5=$ Increased $1-40 \%, 6=$ Increased $41-80 \%, 7=$ Increased more than $80 \%$
We now discuss the results of our empirical analyses to examine the impact of team dispersion on project performance and the moderating role of information technology usage.

\section{Results}

We now describe our statistical estimation model based on the conceptual model shown in Figure 1. First, we specify the main effects model, which is a linear regression model of the relationship between PROJPERF and the independent variables as shown in Equation (1).

$$
\begin{aligned}
\text { PROJPERF }= & \alpha_{0}+\alpha_{1} \text { ITUSAGE }+\alpha_{2} \text { DISPERSION } \\
& +\alpha_{3} \text { AUTONOMY }+\alpha_{4} \text { TEAMSIZE } \\
& +\alpha_{5} \text { PROCMAT }+\alpha_{6} \text { DURATION } \\
& +\alpha_{7} \text { INDUSTR } Y+\varepsilon .
\end{aligned}
$$

Next, we include the interaction term, ITUSAGE $\times$ DISPERSION, to estimate the moderating effect of IT on the relationship between team dispersion and project performance. The interaction effects model is presented in Equation (2).

$$
\begin{aligned}
\text { PROJPERF }= & \alpha_{0}+\alpha_{1} \text { ITUSAGE }+\alpha_{2} \text { DISPERSION } \\
& +\alpha_{3} \text { ITUSAGE } \times \text { DISPERSION } \\
& +\alpha_{4} \text { AUTONOMY }+\alpha_{5} \text { TEAMSIZE } \\
& +\alpha_{6} \text { PROCMAT }+\alpha_{7} \text { DURATION } \\
& +\alpha_{8} \text { INDUSTRY }+\varepsilon,
\end{aligned}
$$

where PROJPERF represents each of the three dependent variables: Cycle time, Quality, and Ontime completion rate.

Table 4 provides the results of ordinary least squares (OLS) regression estimation of Equations (1) and (2). Column (1) provides the predicted signs of 
our estimated parameters based on our research hypotheses. First, we estimate the main effects model as shown in Equation (1). Next, we estimate the interaction effects model in Equation (2) where we include the interaction term, ITUSAGE $\times$ DISPERSION. We present the main and interaction effects estimation results for CYCLE TIME in columns (2) and (3), respectively. The results of the main effects model are consistent with H1. Specifically, the estimated coefficient of ITUSAGE is significant and positive (coeff. $=0.110 ; p=0.005)$, which suggests that greater IT usage is associated with a reduction in project cycle time. However, the coefficient of team DISPERSION is negative but not significant (coeff. $=-0.028 ; p=0.121$ ) and does not support hypothesis $\mathrm{H} 2$.

The results of the interaction effects model shown in column (3) are consistent with H3. The coefficient of ITUSAGE is positive but not significant. However, the coefficient of team DISPERSION is significant and negative (coeff. $=-0.131 ; p=0.046$ ), suggesting that projects with dispersed teams are likely to exhibit longer project cycle times. We observe that the coefficient of the interaction term, ITUSAGE $\times$ DISPERSION, is positive and significant (coeff. $=0.038$; $p=0.082$ ), which suggests that the influence of greater team dispersion on cycle time is moderated through greater levels of ITUSAGE. Hence, our results suggest that IT has a positive, moderating effect on the relationship between team dispersion and project cycle time.

We note that AUTONOMY has a positive association with PROJPERF (coeff. $=0.040 ; p=0.068$ ), which suggests that project teams with greater autonomy of decision making are likely to exhibit lower cycle time. We also note that PROCMAT is positively associated with PROJPERF (coeff. $=0.135 ; p=0.000$ ), which suggests that higher levels of maturity with respect to project planning and management processes are associated with shorter project cycle times. Hence, our preliminary results support our hypotheses with respect to the moderating effects of IT usage on the relationship between team dispersion and project cycle time.

Next, we study the association between our model variables and improvements in project quality and on-time completion rate. The main and interaction effects estimation results for QUALITY are shown in columns (4) and (5), respectively. The results for the main effects model are consistent with $\mathrm{H} 1$ and $\mathrm{H} 2$ (column 4). The coefficient on ITSUAGE is significant and positive (coeff. $=0.121 ; p=0.001$ ), and the coefficient on team DISPERSION is negative (coeff. = $-0.070 ; p=0.001$ ). We observe, however, that the interaction term ITUSAGE $\times$ DISPERSION is not statistically significant in the interaction effects model, 
Table 4 OLS Regression Results of the Main and Interaction Effects on Project Performance

\begin{tabular}{|c|c|c|c|c|c|c|c|}
\hline & \multirow{2}{*}{$\begin{array}{l}\text { Predicted } \\
\text { sign } \\
(1)\end{array}$} & \multicolumn{2}{|c|}{ Cycle time } & \multicolumn{2}{|c|}{ Quality } & \multicolumn{2}{|c|}{ On-time completion rate } \\
\hline & & $(2)$ & $(3)$ & (4) & (5) & $(6)$ & $(7)$ \\
\hline Intercept & & $4.715(0.000)$ & $4.938(0.000)$ & $5.070(0.000)$ & $5.238(0.000)$ & $4.985(0.000)$ & $5.052(0.000)$ \\
\hline IT Usage & + & $0.110^{* * *}(0.005)$ & $0.029(0.350)$ & $0.121^{* \star *}(0.001)$ & $0.060(0.202)$ & $0.148^{* * *}(0.000)$ & $0.124^{* *}(0.047)$ \\
\hline Dispersion & - & $-0.028(0.121)$ & $-0.131^{\star *}(0.046)$ & $-0.070^{* * *}(0.001)$ & $-0.147^{\star \star}(0.017)$ & $-0.032^{*}(0.096)$ & $-0.062(0.216)$ \\
\hline $\begin{array}{l}\text { IT Usage } \\
\times \text { Dispersion }\end{array}$ & + & & $0.038 *(0.082)$ & & $0.029(0.124)$ & & $0.011(0.337)$ \\
\hline Autonomy & & $0.039 *(0.069)$ & $0.040 *(0.068)$ & $0.007(0.398)$ & $0.007(0.396)$ & $-0.001(0.487)$ & $-0.001(0.488)$ \\
\hline Team Size & & $-0.015(0.311)$ & $-0.017(0.300)$ & $-0.033(0.131)$ & $-0.034(0.126)$ & $-0.044^{*}(0.072)$ & $-0.044^{\star}(0.072)$ \\
\hline Process Maturity & & $0.133^{* * *}(0.000)$ & $0.135^{\star \star *}(0.000)$ & $0.223^{* * *}(0.000)$ & $0.225^{* * *}(0.000)$ & $0.242^{* * *}(0.000)$ & $0.243^{* * *}(0.000)$ \\
\hline Project Duration & & $-0.032(0.166)$ & $-0.035(0.147)$ & $-0.021(0.257)$ & $-0.024(0.233)$ & $-0.015(0.328)$ & $-0.016(0.318)$ \\
\hline Adjusted $R^{2}$ & & $8.3 \%$ & $8.6 \%$ & $13.9 \%$ & $14.0 \%$ & $14.6 \%$ & $14.5 \%$ \\
\hline No. of firm obs. & & \multicolumn{2}{|c|}{636} & \multicolumn{2}{|c|}{635} & \multicolumn{2}{|c|}{632} \\
\hline
\end{tabular}

All estimation models contain industry dummies. Variables are defined in Table 2.

$p$-values are reported in parentheses. Standard errors used to compute $p$-values are corrected for heteroskedasticity. $p$-values are computed based on one-tailed $t$-test. ${ }^{\star} p<0.10 ;{ }^{* \star} p<0.05 ;{ }^{* *} p<0.01$. Bold values represent statistically significant regression coefficients.

which indicates that the evidence does not support the moderating effect of IT on project quality.

The OLS estimation results with respect to project COMPLETION RATE are similar to our earlier results for QUALITY. While ITUSAGE is associated with greater on-time project completion rate, team DISPERSION is associated with lower completion rate. We find that the coefficient on the interaction term ITUSAGE $\times$ DISPERSION is positive but not significant. Hence, based on our preliminary results, we observe that the interaction between ITUSAGE and team DISPERSION is positively associated with improvement in project cycle time, which partially supports our hypothesis on the moderating role of IT. Hence, our preliminary OLS results support hypotheses $\mathrm{H} 1$ and $\mathrm{H} 2$ while lending partial support for $\mathrm{H} 3$ only in the case of project cycle time.

In the next phase of our analysis, we split our sample based on the typical volume of information processing required for a project. We use the mean value of information volume (i.e., 3.59) as the cutoff to split the high information volume from low information volume projects. Based on our survey, a sub-sample of 371 projects can be characterized as low information volume projects and the remaining sub-sample of 265 projects exhibit high information processing volume. ${ }^{3}$ We now re-run the OLS estimation models specified in Equations (1) and (2) separately for the split sample, and present these results in Table 5.

First, we describe the results for the sub-sample with projects that are characterized by a high volume of information processing. Our results indicate that ITUSAGE does not have a direct association with project performance in high information volume project environments, and we do not find support for hypothesis H1. On the other hand, team DISPERSION is negatively associated with all three measures of project performance, and our results support $\mathrm{H} 2$ with respect to the negative impact of team dispersion on project performance. We also observe that the interaction term, ITUSAGE $\times$ DISPERSION, is significantly associated with improvement in project CYCLE TIME (coeff. $=0.074 ; p=0.051$ ), QUALITY (coeff. $=0.081$; $p=0.014$ ), and ONTIME RATE (coeff. $=0.053$; $p=0.098)$. Hence, in high information volume environments, our results support hypothesis H3a with respect to the moderating effect of IT usage and its mitigating effect on the relationship between team dispersion and project performance. Our results also indicate that AUTONOMY and TEAMSIZE are negatively associated with project on-time completion rate while project DURATION is associated with lower levels of project quality in high information volume environments. This result may be attributed to potential coordination problems among larger project teams and teams that have autonomous decision making, which is manifested in a lack of adherence to project completion schedules, especially in environments that are characterized by large amounts of information processing and complexity.

We now evaluate the results of OLS estimation in Table 5 for projects that are characterized by low information volume environments. We observe that ITUSAGE is positively associated with project CYCLE TIME and ONTIME RATE while not being significantly associated with project quality. We also report that team DISPERSION is not significantly associated with any of the project performance measures. In other words, when compared with their high information volume counterparts, dispersed project teams in low information environments are not likely to exhibit longer cycle times, lower project quality, or lower on-time completion rates. One reason for this difference may be attributed to the possibility that project performance is less likely to suffer when the volume of information processed and exchanged 
Table 5 Main and Interaction OLS Effects on Project Performance: A Split Sample Analysis Based on Information Volume

\begin{tabular}{|c|c|c|c|c|c|c|}
\hline & \multicolumn{3}{|c|}{ Panel A: High information volume } & \multicolumn{3}{|c|}{ Panel B: Low information volume } \\
\hline & $\begin{array}{l}\text { Cycle time } \\
\text { (1) }\end{array}$ & $\begin{array}{l}\text { Quality } \\
\text { (2) }\end{array}$ & $\begin{array}{l}\text { On-time completion rate } \\
\text { (3) }\end{array}$ & $\begin{array}{l}\text { Cycle time } \\
\text { (4) }\end{array}$ & $\begin{array}{l}\text { Quality } \\
\text { (5) }\end{array}$ & $\begin{array}{c}\text { On-time } \\
\text { completion rate } \\
\text { (6) }\end{array}$ \\
\hline Intercept & $5.410(0.000)$ & $6.085(0.000)$ & $5.821(0.000)$ & $4.691(0.000)$ & $4.906(0.000)$ & $4.774(0.000)$ \\
\hline IT Usage & $-0.130(0.154)$ & $-0.115(0.156)$ & $-0.005(0.484)$ & $0.144^{*}(0.052)$ & $0.102(0.130)$ & $0.140 *(0.066)$ \\
\hline Dispersion & $-0.240 * *(0.040)$ & $-0.368^{* * *}(0.001)$ & $-0.251 * *(0.028)$ & $-0.092(0.155)$ & $-0.065(0.230)$ & $-0.020(0.421)$ \\
\hline IT Usage $\times$ Dispersion & $0.074^{*}(0.051)$ & $0.081^{* *}(0.014)$ & $0.053^{*}(0.098)$ & $0.022(0.254)$ & $0.018(0.300)$ & $0.019(0.310)$ \\
\hline Autonomy & $0.051(0.156)$ & $-0.011(0.411)$ & $-0.077^{*}(0.076)$ & $0.025(0.196)$ & $0.020(0.250)$ & $0.037(0.119)$ \\
\hline Team Size & $-0.052(0.200)$ & $-0.024(0.323)$ & $-0.107^{* *}(0.020)$ & $0.020(0.244)$ & $-0.053^{*}(0.067)$ & $-0.007(0.414)$ \\
\hline Process Maturity & $0.159 * \star *(0.009)$ & $0.288^{\star \star *}(0.000)$ & $0.288^{\star * *}(0.000)$ & $0.105^{\star \star \star}(0.009)$ & $0.138^{* \star *}(0.001)$ & $0.173^{* * *}(0.000)$ \\
\hline Project Duration & $-0.073(0.141)$ & $-0.082^{*}(0.098)$ & $0.017(0.388)$ & $-0.025(0.226)$ & $0.001(0.489)$ & $-0.049 *(0.095)$ \\
\hline Adjusted $R^{2}$ & $7.9 \%$ & $18.5 \%$ & $16.5 \%$ & $8.7 \%$ & $7.2 \%$ & $12.5 \%$ \\
\hline No. of firm-year obs. & 265 & 265 & 264 & 371 & 370 & 368 \\
\hline
\end{tabular}

All estimation models contain industry dummies. Variables are defined in Table 2.

$p$-values are reported in parentheses. Standard errors used to compute $p$-values are corrected for heteroskedasticity. $p$-values are computed based on one-tailed $t$-test. ${ }^{*} p<0.10 ;{ }^{* \star} p<0.05 ;{ }^{* * \star} p<0.01$. Bold values represent statistically significant regression coefficients.

between team members is low. The interaction term, ITUSAGE $\times$ DISPERSION, is insignificant, which suggests that the moderating influence of ITUSAGE on the relationship between team dispersion and project performance is not significant in low information volume environments.

Overall, our results do indicate significant differences between low and high information volume processing environments. Although we find support for hypotheses $\mathrm{H} 2$ and $\mathrm{H} 3$ in high information volume settings with respect to the association between team dispersion and the moderating role of IT usage, our results do not support these hypotheses in low information volume environments.

An important consideration in our estimation models is the potential for endogeneity. That is, what if high-performing projects are more likely to invest in IT and thereby exhibit higher levels of IT usage? We conduct a Durbin-Wu-Hausman test using the industry mean of IT usage as the instrumental variable to check for the presence of endogeneity. ${ }^{4}$ As the primary industry affiliation of each firm in our sample is available, we calculate the mean value of industry-level IT usage for each of the industry subgroups in our sample. We note that the industry mean value of IT usage is unlikely to be endogenously related to project-level performance, as there are various factors outside the control of an individual firm or project manager that determine industrylevel IT usage. The $F$-statistics for the Hausman test results are equal to $0.48(p$-value $=0.49), 0.94(p$ value $=0.33)$, and $0.31 \quad(p$-value $=0.58)$ for the CYCLE TIME, QUALITY, and ONTIME RATE estimation models, respectively. Based on the lack of significance of the Hausman test results, we conclude that endogeneity is unlikely to be of significant concern in our estimation results.

\section{Robustness Checks}

There are four principal assumptions that justify our use of OLS estimation: (i) linearity of the relationship between dependent and independent variables, (ii) independence of the errors, (iii) homoscedasticity of the errors, and (iv) normality of the error distribution in our regression models. If any of these assumptions are violated, the OLS results may be biased and misleading (Belsley et al. 1980). We conduct various diagnostic tests to verify if our data meet those assumptions.

First, we construct a scatter plot between the observed and predicted values to check for the presence of non-linearity in our data. We observe that the plot is symmetrically distributed along a diagonal line, which indicates that non-linearity is not of concern in our data. Second, we use cross-sectional data from a single year and our sample does not contain more than a single observation from the same firm. Therefore, we are not concerned about cross-sectional or time-series correlations in our regressions. Next, our estimation results include $t$-statistics and $p$-values that have been corrected for heteroscedasticity in the variance of errors. Finally, we also conduct tests to check for normality of the error distribution. A plot of the residuals shows a higher degree of kurtosis compared with a normal distribution. The test results indicate that the residuals are not normally distributed (e.g., $p$-values for the Shapiro-Wilk test and Anderson-Darling tests are both less than 0.01). Nonnormality of the residuals is likely caused by the distribution of the dependent variables (that are measured as discrete, ordered variables). However, for large sample sizes as in our study, violation of the normality assumption is virtually inconsequential. Based on the central limit theorem, the test statistic will asymptotically follow the appropriate 
distribution even in the absence of error normality (Brooks 2008, p. 164).

We also deploy a path modeling approach called partial least squares (PLS) that represents an alternative approach to structural equation modeling and overcomes the limitations associated with OLS estimation models (Tenenhaus et al. 2005, Wold 1985). One of the advantages of PLS over covariance-based SEM is that PLS is distribution free. PLS does not require a distributional assumption of multivariate normality (Joreskog and Wold 1982, Wold 1982, 1985). Hence, we estimate our models using PLS, using a bootstrap re-sampling procedure that is used to assess the significance of PLS coefficient estimates.

We present the PLS results for the full data set in Table 6. The PLS results are qualitatively similar to the OLS results, with the exception that the interaction term ITUSAGE $\times$ DISPERSION is statistically significant for CYCLE TIME and QUALITY. In Table 7, we present the PLS estimation results for the split sample analysis based on project information volume. We observe that the PLS and OLS results are qualitatively identical. The results suggest that while team dispersion is adversely associated with project performance, the interaction effect of ITUSAGE and team DISPERSION on project performance is positive and significant. Hence, our PLS results support H3 with respect to the moderating influence of IT and its mitigating effect on the negative relationship of team dispersion and project performance. They also support our earlier results with respect to the significance of the moderation effect of IT usage in projects characterized by high information volume and processing requirements.

\section{Conclusions}

As business projects become more globally distributed, ensuring that such distributed projects deliver results becomes increasingly important. In this study, we extend prior theory on virtual teams and geographic team dispersion to specifically examine the role of new types of IT applications as a moderator of the relationship between team dispersion

Table 6 PLS Regression Results of the Main and Interaction Effects on Project Performance

\begin{tabular}{|c|c|c|c|c|c|c|c|}
\hline & \multirow{2}{*}{$\begin{array}{l}\text { Predicted } \\
\text { sign } \\
(1)\end{array}$} & \multicolumn{2}{|c|}{ Cycle time } & \multicolumn{2}{|c|}{ Quality } & \multicolumn{2}{|c|}{ On-time completion rate } \\
\hline & & (2) & (3) & (4) & (5) & (6) & (7) \\
\hline IT Usage & + & $0.124^{\star \star \star}(0.006)$ & $0.026(0.401)$ & $0.138^{* * *}(0.001)$ & $0.067(0.182)$ & $0.161^{* * *}(0.000)$ & $0.136 *(0.056)$ \\
\hline Dispersion & - & $-0.046(0.131)$ & $-0.229 * *(0.046)$ & $-0.119 * * *(0.000)$ & $-0.250^{* * *}(0.005)$ & $-0.050 *(0.081)$ & $-0.097(0.239)$ \\
\hline $\begin{array}{l}\text { IT Usage } \\
\quad \times \text { Dispersion }\end{array}$ & + & & $0.232 *(0.094)$ & & $0.167^{*}(0.078)$ & & $0.060(0.352)$ \\
\hline Autonomy & & $0.055(0.108)$ & $0.055^{\star}(0.061)$ & $0.006(0.442)$ & $0.007(0.417)$ & $-0.004(0.456)$ & $-0.004(0.460)$ \\
\hline Team Size & & $-0.025(0.305)$ & $-0.027(0.271)$ & $-0.050(0.106)$ & $-0.051(0.152)$ & $-0.060 *(0.055)$ & $-0.061^{*}(0.055)$ \\
\hline Process Maturity & & $0.205^{\star \star \star}(0.000)$ & $0.207^{\star * *}(0.000)$ & $0.302^{* \star *}(0.000)$ & $0.304^{* * *}(0.000)$ & $0.300 * * *(0.000)$ & $0.300 * * *(0.000)$ \\
\hline Project Duration & & $-0.048(0.144)$ & $-0.053(0.147)$ & $-0.030(0.241)$ & $-0.034(0.245)$ & $-0.020(0.326)$ & $-0.021(0.326)$ \\
\hline$R^{2}$ & & $11.1 \%$ & $11.5 \%$ & $16.4 \%$ & $16.6 \%$ & $16.7 \%$ & $16.8 \%$ \\
\hline No. of firm obs. & & \multicolumn{2}{|c|}{636} & \multicolumn{2}{|c|}{635} & \multicolumn{2}{|c|}{632} \\
\hline
\end{tabular}

All estimation models contain industry dummies. Variables are defined in Table 2.

$p$-values are reported in parentheses. $p$-values are computed based on one-tailed $t$-test. ${ }^{*} p<0.10$; ${ }^{* *} p<0.05$; ${ }^{* * *} p<0.01$. Bold values represent statistically significant regression coefficients.

Table 7 PLS Regression Results Based on Split Sample Analysis by Information Volume

\begin{tabular}{|c|c|c|c|c|c|c|}
\hline & \multicolumn{3}{|c|}{ Panel A: high information volume } & \multicolumn{3}{|c|}{ Panel B: low information volume } \\
\hline & $\begin{array}{l}\text { Cycle time } \\
\text { (1) }\end{array}$ & $\begin{array}{l}\text { Quality } \\
\text { (2) }\end{array}$ & $\begin{array}{c}\text { On-time } \\
\text { completion rate } \\
\text { (3) }\end{array}$ & $\begin{array}{l}\text { Cycle time } \\
\text { (4) }\end{array}$ & $\begin{array}{l}\text { Quality } \\
\text { (5) }\end{array}$ & $\begin{array}{c}\text { On-time } \\
\text { completion rate } \\
\text { (6) }\end{array}$ \\
\hline IT Usage & $-0.150(0.130)$ & $-0.126(0.169)$ & $-0.005(0.480)$ & $0.161^{*}(0.075)$ & $0.113(0.136)$ & $0.151^{*}(0.083)$ \\
\hline Dispersion & $-0.376^{\star \star}(0.044)$ & $-0.587^{* * *}(0.001)$ & $-0.373^{\star *}(0.019)$ & $-0.173(0.150)$ & $-0.117(0.242)$ & $-0.030(0.440)$ \\
\hline IT Usage $\times$ Dispersion & $0.436 *(0.053)$ & $0.475^{\star *}(0.018)$ & $0.291^{*}(0.084)$ & $0.128(0.258)$ & $0.101(0.312)$ & $0.098(0.337)$ \\
\hline Autonomy & $0.066(0.134)$ & $-0.015(0.401)$ & $-0.091^{*}(0.070)$ & $0.033(0.274)$ & $0.029(0.281)$ & $0.052(0.164)$ \\
\hline Team Size & $-0.073(0.193)$ & $-0.035(0.305)$ & $-0.135^{* *}(0.013)$ & $0.032(0.265)$ & $-0.084^{*}(0.056)$ & $-0.011(0.425)$ \\
\hline Process Maturity & $0.217^{* * *}(0.010)$ & $0.360 * * *(0.000)$ & $0.318 * * *(0.000)$ & $0.193^{\star * *}(0.000)$ & $0.209 * * *(0.000)$ & $0.236^{* * *}(0.000)$ \\
\hline Project Duration & $-0.099(0.164)$ & $-0.108^{*}(0.092)$ & $0.021(0.390)$ & $-0.043(0.224)$ & $0.001(0.492)$ & $-0.075^{\star}(0.094)$ \\
\hline$R^{2}$ & $14.0 \%$ & $24.2 \%$ & $21.7 \%$ & $13.5 \%$ & $11.6 \%$ & $16.6 \%$ \\
\hline No. of firm-year obs. & 265 & 265 & 264 & 371 & 370 & 368 \\
\hline
\end{tabular}

All estimation models contain industry dummies. Variables are defined in Table 2.

$p$-values are reported in parentheses. $p$-values are computed based on one-tailed $t$-test. ${ }^{\star} p<0.10 ;{ }^{* *} p<0.05 ;{ }^{* *} p<0.01$. Bold values represent statistically significant regression coefficients. 
and project performance. Our hypotheses, which we empirically test using a relatively large sample of project data, show that team dispersion and distribution across multiple locations distorts project performance and has a negative association with project cycle time, quality, and completion rate. However, our results show that IT mitigates the negative effect of project team dispersion on project performance. In other words, IT usage has a positive, moderating effect on the relationship between team dispersion on project performance, and our results suggest that IT's role as an enabler of project coordination and management across dispersed teams is critical in determining project outcomes. Furthermore, our results indicate that the positive effect of IT is significant in high information volume settings that exhibit a greater degree of information processing requirements. In such environments, ITenabled capabilities play a critical role in moderating the effect of team dispersion on project cycle time, quality, and on-time completion rate. Considering the increasing importance of globally distributed project teams, our study provides empirical evidence to support the role of IT in managing project teams across multiple locations and thereby extends the framework developed by Amaral et al. (2011) to study distributed product development.

Prior research on virtual teams has primarily focused on empirical studies that measure the impact of co-location of R\&D teams on the frequency and richness of communication among teams, and their subsequent impact on product development performance (Leiponen and Helfat 2011, Song et al. 2007, Van den Bulte and Moenaert 1998). Although most studies report that team co-location has a beneficial impact on project/team communication and outcomes, and document the coordination challenges associated with geographically dispersed teams, they do not specifically measure the impact of IT mechanisms that provide the enabling coordination infrastructure for virtual teams. Our study aims to address this critical gap in the literature by developing a model based on information-intensive project work and empirically testing the role of commonly used IT applications using project-level data. Although our results support conventional wisdom with respect to the negative effects of team dispersion on project performance, we extend this stream of research by empirically testing the conditions under which IT mitigates the negative effects of team dispersion. By showing that the moderation impact of IT is significant in high information volume environments (which are likely to entail higher information processing requirements), we extend prior research on the integration of knowledge work across geographically dispersed project teams.
Our study has several limitations. First, we do not account for the use of IT by individual contributors or non-managerial personnel who may have different IT usage patterns from project/program managers. Second, our survey does not provide any information on the timeline of implementation of different types of software applications and changes in IT usage across time. Third, our data collection was conducted using the key informant method, which represents the opinion of individual project managers. Although we collected data from multiple respondents for a small subset of our sample, future research will include industry-specific case studies and longitudinal data collected over the project lifecycle and include more granular project data. We believe that future studies should be supplemented with detailed archival data collection to mitigate the potential problems associated with such effects.

Our results imply that firms will realize significant benefits in terms of project outcomes if IT is implemented in a manner to support higher bandwidth communication among virtual teams. Our research framework sheds new light on the levers that firms can employ to motivate adoption of new types of information technologies among project teams. It bridges the knowledge-based view of the firm which argues for greater dispersion of $R \& D$ teams to improve firm innovation capabilities with a conflicting school of thought emanating from organizational economics research, which favors co-location of $R \& D$ teams. By showing that the positive, moderating effect of IT is significant only in high information volume projects, we are able to provide a more nuanced understanding of the project conditions that lend themselves to the successful usage of IT applications for project management. Hence, our study breaks new ground in the area of IT-enabled capabilities and their role in managing projects in globally distributed project work.

\section{Acknowledgments}

Feedback received from Nitin Joglekar, Satish Nambisan, Kingshuk Sinha, Kathy Stecke; useful insights and suggestions for improvement from the guest editors, associate editor, and reviewers, as well as participants at the University of California San Diego and University of Texas at Dallas seminar series, and the POMS 2009 Annual Conference in Orlando, FL, are gratefully acknowledged.

\section{Notes}

${ }^{1}$ We focus on managers who use IT for making project decisions and coordinating and managing project workflows, instead of individual users who use IT for their functional needs but are not involved in project management. 
${ }^{2}$ http: / / hbr.org/2007/11/ are-your-engineers-talking-to-oneanother-when-they-should/ar/1

${ }^{3}$ The size of sub-samples varies slightly for different performance measures. We note that our results are consistent even if we use the median information volume as the cutoff for splitting the sample into high- versus low-information volume projects.

${ }^{4}$ Our approach is similar to the method proposed by Lev and Sougiannis (1996) to use the industry-level mean as an instrumental variable for a firm-specific explanatory variable in our regression models.

\section{References}

Adler, P. S. 1995. Interdepartmental interdependence and coordination: The case of the design/manufacturing interface. Organ. Sci. 6(2): 147-167.

Allen, T. J. 1977. Managing the Flow of Technology. MIT Press, Cambridge, MA.

Allen, T. J. 2007. Architecture and communication among product development engineers. Calif. Manag. Rev. 49(2): 2341.

Amaral, J., E. G. Anderson Jr., G. G. Parker. 2011. Putting it together: How to succeed in distributed product development. Sloan Manag. Rev. 52(2): 51-58.

Ancona, D. G., D. F. Caldwell. 1992. Bridging the boundary: External activity and performance in organizational teams. Admin. Sci. Q. 37(4): 634-665.

Anderson, E. G. Jr., G. G. Parker. 2013. Integration of global knowledge networks. Prod. Oper. Manag. 22(6): 14461463.

Argyres, N. S., B. Silverman. 2004. R\&D, organizational structure, and the development of corporate technological knowledge. Strategic Manag. J. 25(1): 929-958.

Baba, Y., K. Nobeoka. 1998. Toward knowledge-based product development: The 3-D CAD model of knowledge creation. Res. Policy 26: 643-659.

Bala, R., V. Krishnan, W. Zhu. 2010. Distributed development and product line decision making. Working paper, The University of California, San Diego, CA.

Banker, R. D., I. R. Bardhan, H. Chang, S. Lin. 2006a. Plant information systems, manufacturing capabilities and plant performance. MIS Quarterly 30(2): 315-337.

Banker, R. D., I. R. Bardhan, O. Asdemir. 2006b. Understanding the impact of collaboration software on product design and development. Inf. Sys. Res. 17(4): 352-373.

Bardhan, I. R., V. Krishnan, S. Lin. 2007a. Project performance and the enabling role of information technology: An exploratory study on the role of alignment. Manuf. Serv. Oper. Manag. 9(4): 579-595.

Bardhan, I., J. Whitaker, S. Mithas. 2007b. Antecedents and impact of production and support outsourcing in manufacturing plants. Prod. Oper. Manag. 16(6): 747-762.

Barua, A., C. Kriebel, T. Mukhopadhyay. 1995. Information technology and business value: An analytic and empirical investigation. Inf. Sys. Res. 6(1): 3-23.

Bas, C. L., C. Sierra. 2002. Location versus home country advantages in R\&D activities: Some further results on multinationals location strategies. Res. Policy 31(4): 589-609.

Becker, F., F. Steele. 1995. Workplace by Design. Josey-Bass, San Francisco, CA.

Belsley, D. A., E. Kuh, R. E. Welsch. 1980. Regression Diagnostics: Identifying Influential Data and Sources of Collinearity. John Wiley, New York.
Bensaou, M., M. Earl. 1998. The right mind-set for managing information technology. Harvard Bus. Rev. 76(5): 119-128.

Brooks, C. 2008. Introductory Econometrics for Finance, 2nd edn. Cambridge University Press, United Kingdom.

Chacar, A. S., M. B. Lieberman. 2003. Organizing for technological innovation in the U.S. pharmaceutical industry. Adv. Strategic Manag. 20: 317-340.

Conner, K. R., C. K. Prahalad. 1996. A resource based view of the firm: Knowledge versus opportunism. Organ. Sci. 7(5): 477-501.

Cramton, C., P. Hinds. 2005. Subgroup dynamics in internationally distributed teams: Ethnocentrism or cross-national learning? Res. Organ. Behav. 26: 231-263.

Daft, R. L., R. H. Lengel. 1986. Organizational information requirements, media richness, and structural design. Manage. Sci. 32(5): 554-571.

Eppinger, S. D., A. R. Chitkara. 2006. The new practice of global product development. MIT Sloan Manag. Rev. 47(4): 22-30.

Erat, S., V. Krishnan. 2012. Managing delegated search over design spaces. Manage. Sci. 58(3): 606-623.

Espinosa, J. A., C. Pickering. 2006. The effect of time separation on coordination processes and outcomes: A case study. Proceedings of the 39th Hawaii International Conference on System Sciences (HICSS'06): 25-35.

Furman, J. L., M. K. Kyle, I. M. Cockburn, R. Henderson. 2006. Public and private spillovers, location \& the productivity of pharmaceutical research. NBER Working Paper No. 12509, Cambridge, MA.

Grant, R. 1996. Toward a knowledge-based theory of the firm. Strategic Manag. J. 17(Winter Special Issue): 109-122.

Griffin, A., J. R. Hauser. 1996. Integrating R\&D and marketing: A review and analysis of the literature. J. Prod. Innov. Manag. 13 (3): 191-215.

Griffith, T. L., J. E. Sawyer, M. A. Neale. 2003. Virtualness and knowledge in teams: Managing the love triangle of organizations, individuals, and information technology. MIS Quarterly 27(2): 265-287.

Harter, D. E., M. S. Krishnan, S. Slaughter. 2000. Effects of process maturity on quality, cycle time, and effort in software product development. Manage. Sci. 46(4): 451-466.

Himmelstein, D. U., A. Wright, S. Woolhandler. 2010. Hospital computing and the costs and quality of care: A national study. The Am. J. Med. 123(1): 40-46.

Hinds, P., S. Kiesler. 1995. Communication across boundaries: Work, structure, and use of communication technologies in a large organization. Organ. Sci. 6(4): 373-393.

Hoegl, M. M., K. Weinkauf, H. G. Gemuenden. 2004. Interteam coordination, project commitment, and teamwork in multiteam R\&D projects: A longitudinal study. Organ. Sci. 15(1): $38-55$.

Joreskog, K. G., H. Wold. 1982. The ML and PLS techniques for modeling with latent variables: Historical and comparative aspects. K. G. Joreskog, H. Wold, eds. Systems Under Indirect Observation: Causality, Structure, Prediction. North-Holland, Amsterdam, 263-270.

Kahn, K. B., E. F. McDonough III. 1997. An empirical study of the relationships among co-location, integration, performance, and satisfaction. J. Prod. Innov. Manag. 14(3): 161-178.

Kiesler, S., J. N. Cummings. 2002. What do we know about proximity in work groups? A legacy of research on physical distance. P. Hinds, S. Kiesler, eds. Distributed Work. MIT Press, Cambridge, MA, 57-80.

Kogut, B., U. Zander. 1993. Knowledge of the firm and the evolutionary theory of the multinational corporation. J. Int. Bus. Stud. 24(4): 625-646. 
Krishnan, V., C. H. Loch. 2005. A retrospective look at production and operations management articles on new product development. Prod. Oper. Manag. 14(4): 433-441.

Krishnan, V., K. Ramachandran. 2011. Integrated product architecture and pricing for managing sequential innovation. Manage. Sci. 57(November): 2040-2053.

Krishnan, V., K. Ulrich. 2001. Product development decisions: A review of the literature. Manage. Sci. 47(1): 1-21.

Krishnan, M. S., C. Kriebel, S. Kekre, T. Mukhopadhyay. 2000. An empirical analysis of productivity and quality in software products. Manage. Sci. 46(6): 745-759.

Kumar, N. 2001. Determinants of location of overseas R\&D activity of multinational enterprises: The case of US and Japanese corporations. Res. Policy 30(1): 159-174.

Leiponen, A., C. E. Helfat. 2011. Location, decentralization, and knowledge sources for innovation. Organ. Sci. 22(3): 641-658.

Lev, B., T. Sougiannis. 1996. The capitalization, amortization and value-relevance of R\&D. J. Acct. Econ. 21(1): 107-138.

Majchrzak, A., R. E. Rice, A. Malhotra, N. King, S. Ba. 2000. Technology adaptation: The case of a computer-supported interorganizational virtual team. MIS Quarterly 24(4): 569-600.

Maltz, E., A. K. Kohli. 1996. Market intelligence dissemination across functional boundaries. J. Mark. Res. 33(1): 47-61.

Martins, L. L., L. L. Gilson, M. T. Maynard. 2004. Virtual teams: What do we know and where do we go from here? J. Manag. 30(6): 805-835.

Marwaha, S., S. Patil, N. Singh. 2007. Using IT to speed up clinical trials. McKinsey Quarterly 1: 12-19.

Massey, A. P., M. M. Montoya-Weiss. 2006. Unraveling the temporal fabric of knowledge conversion: A model of media selection and use. MIS Quarterly 30(1): 99-114.

Massey, A. P., M. M. Montoya-Weiss, Y.-T. Hung. 2003. Because time matters: Temporal coordination in global virtual teams. J. Manag. Inf. Sys. 19(4): 129-155.

Maznevski, M. L., K. M. Chudoba. 2000. Bridging space over time: Global virtual team dynamics and effectiveness. Organ. Sci. 11 (5): 473-492.

McGrath, M., M. Iansiti. 1998. Envisioning IT-enabled innovation. PRTM Insight Mag. Fall/Winter: 2-10.

McKelvey, M., H. Alm, M. Riccaboni. 2003. Does co-location matter for formal knowledge collaboration in the Swedish biotechnology-pharmaceutical sector? Res. Policy 32(3): 483501.

Mendelson, H. 2000. Organizational architecture and success in the information technology industry. Manage. Sci. 46(4): 513529.

Metters, R., A. Maruchek. 2007. Service management-academic issues and scholarly reflections from operations management researchers. Dec. Sci. 38(2): 195-214.

Miller, J. G., A. V. Roth. 1994. A taxonomy of manufacturing strategies. Manage. Sci. 40(3): 285-304.

Nambisan, S. 2003. Information systems as a reference discipline for new product development. MIS Quarterly 27(1): 1-18.

O'Leary, M. B., J. N. Cummings. 2007. The spatial, temporal, and configurational characteristics of geographic dispersion in teams. MIS Quarterly 31(3): 433-452.

O'Leary, M. B., M. Mortensen. 2010. Go (con)figure: Subgroups, imbalance, and isolates in geographically dispersed teams. Organ. Sci. 21(1): 115-131.

Parker, G. G., E. G. Anderson Jr. 2002. From buyer to integrator: The transformation of the supply chain manager in the vertically disintegrating firm. Prod. Oper. Manag. 11(1): 75-91.

Podsakoff, P. M., S. B. MacKenzie, J. Lee, N. P. Podsakoff. 2003. Common method biases in behavioral research: A critical review of the literature and recommended remedies. J. Appl. Psychol. 88(5): 879-903.

Polzer, J. T., C. B. Crisp, S. L. Jarvenpaa, J. W. Kim. 2006. Extending the faultline model to geographically dispersed teams: How collocated subgroups can impair group functioning. Acad. Manag. J. 49(4): 679-692.

Sanders, N. R. 2007. An empirical study of the impact of e-business technologies on organizational collaboration and performance. J. Oper. Manag. 25(6): 1332-1347.

Saunders, C., C. Van Slyke, D. R. Vogel. 2004. My time or yours? Managing time vision in global virtual teams. Acad. Manag. Exec. 18(1): 19-31.

Schmidt, J. B., M. M. Montoya-Weiss, A. P. Massey. 2001. New product development decision-making effectiveness: Comparing individuals, face-to-face teams, and virtual teams. Decis. Sci. 32(4): 575-600.

Singh, J. 2008. Distributed R\&D, cross-regional knowledge integration and quality of innovative output. Res. Policy 37(1): 77-96.

Song, M., H. Berends, H. van der Bij, M. Weggeman. 2007. The effect of IT and co-location on knowledge dissemination. J. Prod. Innov. Manag. 24(1): 52-68.

Sosa, M. E., S. Eppinger, M. Pich, D. McKendrick, S. Stout. 2002. Factors that influence technical communication in distributed product development: An empirical study in the telecommunications industry. IEEE Trans. on Eng. Manag. 49 (1): $45-58$.

Sosa, M., S. Eppinger, C. Rowles. 2004. The misalignment of product architecture and organizational structure in complex product development. Manage. Sci. 50(12): 1674-1689.

Sosa, M. E., S. D. Eppinger, C. M. Rowles. 2007. Are your engineers talking to one another when they should? Harvard Bus. Rev. 85(11): 133-142.

Stalk, G., Jr., T. M. Hout. 1990. Competing Against Time. Free Press, New York.

Tatikonda, M. V., M. Montoya-Weiss. 2001. Integrating operations and marketing perspectives of product innovation: The influence of organizational process factors and capabilities on development performance. Manage. Sci. 47(1): 151172.

Tenenhaus, M., V. E. Vinzi, Y.-M. Chatelin, C. Lauro. 2005. PLS path modeling. Comput. Stat. Data Anal. 48(1): 159-205.

Terwiesch, T., C. Loch, A. De Meyer. 2002. Exchanging preliminary information in concurrent engineering. Organ. Sci. 13(4): 402-419.

Ulrich, K., D. Ellison. 2005. Beyond make-buy: Internalization and integration of design and production. Prod. Oper. Manag. 14 (3): 315-330.

Van den Bulte, C., R. K. Moenaert. 1998. The effects of R\&D team co-location on communication patterns among R\&D, marketing, and manufacturing. Manage. Sci. 44(11): S1-S18.

Vickery, S., C. Droge, T. P. Stank, T. J. Goldsby, R. E. Markland. 2004. The performance implications of media richness in a business-to-business service environment: Direct versus indirect effects. Manage. Sci. 50(8): 1106-1119.

Weill, P. 1992. The relationship between investment in information technology and firm performance: A study of the valve manufacturing sector. Inf. Sys. Res. 3(4): 307-333.

Williams, L. J., M. R. Buckley, J. A. Cote. 1989. Lack of method variance in self-reported affect and perceptions at work: Reality or artifact. J. Appl. Psychol. 74(3): 462-468.

Wold, H. 1982. Soft modeling: The basic design and some extensions. K. G. Joreskog, H. Wold, eds. Systems under Indirect Observation, Part 2. North-Holland, Amsterdam, 154. 
Wold, H. 1985. Systems analysis by partial least squares. P. Nijkamp, H. Leitner, N. Wrigley, eds. Measuring the Unmeasurable. Marinus Nijhoff, Dordrecht, Germany, 221-251.

Wu, Y., K. Ramachandran, V. Krishnan. 2010. Managing projects with present-biased agents. Working paper, The University of California, San Diego, CA.

Yassine, A., K. C. Kim, T. Roemer, M. Holweg. 2004. Investigating the role of IT in customized product design. Prod. Plann. Control 15(4): 422-434.

\section{Supporting Information}

Additional Supporting Information may be found in the online version of this article:

Appendix S1: Survey Questionnaire 